\title{
THE QUALITY OF THE PROPAGATION PREDICTION WITH RADIO MOBILE FOR TETRA COMMUNICATION SYSTEMS
}

\author{
Iulian BOULEANU, Robert HELBET, Neculai CRAIU \\ "Nicolae Bălcescu" Land Forces Academy, Sibiu, Romania \\ ibouleau@gmail.com, helbet@gmail.com, n.craiu@yahoo.ro
}

\begin{abstract}
We present a short analysis of the prediction quality offered by Radio Mobile application when used for frequency band of TETRA systems in Romania. The simulation results provided by Radio Mobile were compared against own measurements made in multiple locations in Sibiu city. The correlation coefficient between simulated and measured values of signal power was of 0.907 while the maximum variation between data in the strings was $9.6 \mathrm{~dB}$ and the average standard deviation was $4.4 \mathrm{~dB}$. These results indicate that the radio propagation model 'Two-ray Irregular Terrain Model Point to Point' (ITM) provides a prediction capability that offers a reliable planning of the radio coverage of TETRA systems.
\end{abstract}

\section{Keywords: RF propagation, prediction quality, TETRA, Radio Mobile}

\section{Introduction}

The results of technological developments in communications and IT have materialized in recent decades in the appearance on the market of an exceptionally broad range of technologies. These technologies are most often subject to globally recognized standardizations and are implemented in wireless communication systems with application requirements and dimensions extremely heterogeneous. At a short analysis of these technologies and systems, one can found two major trends: the need of increased voice and data services with high transfer rates doubled by simultaneous need for increased requirement of mobility and rapid deployment of new systems in working environments more and more diverse.

Terrestrial Trunked Radio (TETRA) is one of the new generation communication technologies that provide a variety of services under increased mobility to the users [1], [2]. Originally TETRA systems have been designed to ensure secure voice and data services for governmental structures in times of peace and crisis. In past years the armies of developed countries tend to use this technology to provide services, including in situations of war, while including TETRA equipments at tactical echelons endowment.

Deployability and mobility requirements of new generation radio systems confronts the planners with a number of challenges on the design and installation in due time, under various environmental conditions and frequency bands. To this end, planners of mobile and/or of deployable communication systems use software applications for radio coverage planning and for traffic optimization according to the organization's needs. Many software applications are present nowadays on the market [3], [4], [5] and they allow automation of activities belonging the 
planning process, such as:

- identification of fixed stations locations for the calculation and optimization of the system's coverage;

- identification of repeater locations in order to optimize coverage on a specific route or the quality of radio links within the network;

- calculation of the radio link parameters.

To perform these operations, planning applications made use of:

- digital maps which enable threedimensional modeling of the land;

- clutter-type maps containing data on the type of land in the receiving point for estimating the additional attenuation introduced by environment from the point of reception to that of emission (from the total loss of radio link), and,

- propagation models point to point and point to surface, to estimate parameters and quality of radio link parameters depending on a number of variables set by the planner, or on network, equipment and propagation environment.

Radio Mobile is a freeware application made by Roger Coude which can be downloaded from [5]. Application versatility is used by radio amateurs and systems planners specifically for planning direct radio links with communications equipment using frequencies above $20 \mathrm{MHz}$.

Application is based on Irregular Terrain Model in Point to Point Mode (ITM PTP). The accuracy of the model is not general, but depends on type of terrain, on type of built environment (urban) on type of service (broadcast - over long distances), etc. There are models dedicated for mountain zones, and generally no model is such comprehensive to take into account all peculiarities and variables of the radio link, therefore the model's accuracy is variable in function of specific input data [6].

ITM PTP comes from Longley Rice model which was devoted to analysis of a general environment. Its limitations are: a) dense urban areas; b) cases of use of hand held radios found below the clutter surface. The model is however reliable in cases of mobile antennas or of mast located antennas.

Present analysis seeks to determine the degree of confidence that radio network planners can have in forecasting results achieved by Radio Mobile application for TETRA mobile radio systems.

\section{Materials and method}

The study is based on comparing data obtained by measuring the reception level in a number of locations situated in the coverage area of a TETRA base station with data expected to be obtained (predicted) in the respective measuring points by simulating the TETRA network by Radio Mobile application [7], [8].

\subsection{Design of the simulation}

To obtain the propagation forecasting data, Radio Mobile application version 11.6.0 was used. Digital elevation maps required for $3 \mathrm{D}$ environment simulation in which measurements were performed, are extracted from Shuttle Radar Topography Mission (SRTM) and have a resolution of 1 $\operatorname{arcsec}$ [5], [6], [9].

Simulated TETRA system has the parameters presented in Table 1, which belong to a station Motorola MTS 2 [10] with two transmission frequencies and to a Kathrein K751637 antenna [11].

\begin{tabular}{|c|c|}
\hline \multicolumn{2}{|c|}{ Base Station } \\
\hline Type & Motorola MTS 2 \\
\hline $\begin{array}{l}\text { Frequency } \\
\text { range }\end{array}$ & $\begin{array}{l}350-400 \mathrm{MHz}, \\
403-470 \mathrm{MHz}\end{array}$ \\
\hline $\begin{array}{l}\text { Frequency } \\
\text { Channel }\end{array}$ & $393.239 \mathrm{MHz}$ \\
\hline $\begin{array}{l}\text { Transmit } \\
\text { Power }\end{array}$ & 25 Watt \\
\hline \multirow[t]{2}{*}{ Sensitivity } & $\begin{array}{c}-120 \mathrm{dBm} \text { static at } 4 \% \\
\text { BER }\end{array}$ \\
\hline & $\begin{array}{c}-113,5 \mathrm{dBm} \text { faded at } 4 \% \\
\text { BER }\end{array}$ \\
\hline \multicolumn{2}{|r|}{ Antenna } \\
\hline Type & Kathrein K751637 \\
\hline Frequency & $380-400 \mathrm{MHz}$ \\
\hline
\end{tabular}




\begin{tabular}{|c|c|}
\hline range & \\
\hline Gain & $7.5 \mathrm{dBi}$ \\
\hline Impedance & $50 \mathrm{ohm}$ \\
\hline Polarization & Vertical \\
\hline Height & $12 \mathrm{~m}$ \\
\hline
\end{tabular}

Table 1. Parameters of the analyzed system

TETRA mobile station parameters used in the simulation are identical to the base station, with the only difference that the receiving antenna height was set at $2 \mathrm{~m}$. Horizontal and vertical radiation patterns are shown in Figure 1.

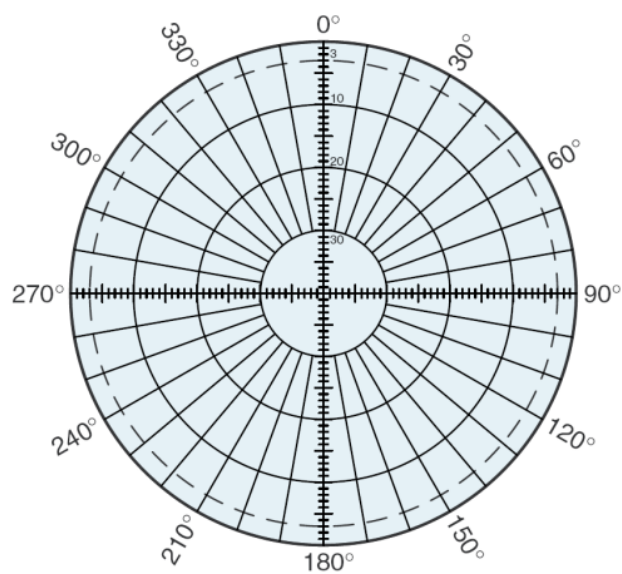

Horizontal pattern $-\mathrm{V}$ polarization

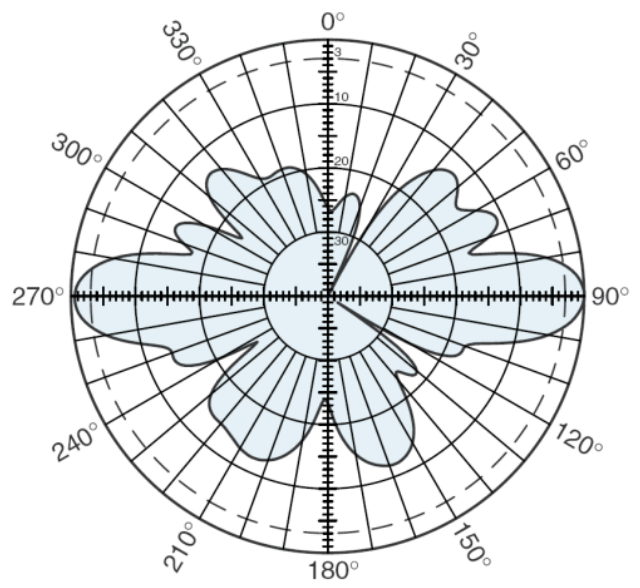

Vertical pattern $-\mathrm{V}$ polarization

Figure 1. Radiation patterns of Kathrein K751637 antenna [11]

\subsection{Measurement system}

Power level measurement of the signal emitted by Motorola MS 2 station was made by a system composed of a swept spectrum analyzer Rohde \& Schwarz FSH 3 and a miniature E-field probe model EM-EC
Scan, Credence Technologies (Figure 2).

Table 2 presents the settings of the spectrum analyzer used to measure the signal level in the TETRA radio channel over the coverage area. It was set to sweep in channel power mode.

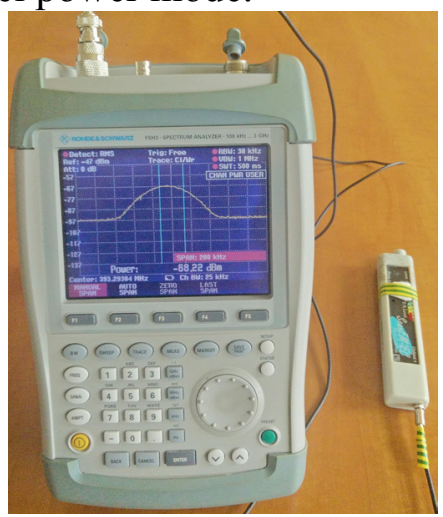

Figure 2. Measurement system composed by the spectrum analyzer FSH 3 and the field probe Scan EM-EC

\begin{tabular}{|c|c|}
\hline RBW (Radio Bandwidth) & $10 \mathrm{kHz}$ \\
\hline VBW (Video bandwidth) & $1 \mathrm{MHz}$ \\
\hline SWT (Sweep Time) & $500 \mathrm{~ms}$ \\
\hline Channel Bandwidth & $25 \mathrm{kHz}$ \\
\hline Center Frequency & $393 \mathrm{MHz}$ \\
\hline Span & $100 \mathrm{kHz}$ \\
\hline
\end{tabular}

Table 2. Measurement system settings

Measurements were performed in 31 locations in Sibiu city. The measurement points were chosen on the main roads, at the height of a car, distanced to at least $300 \mathrm{~m}$ from each other, both around the base station and along main roads, so that we could find the signal level for radio links made at distances between $60 \mathrm{~m}$ and 3.34 $\mathrm{km}$. In each point, measurements in three positions of the receiving sensor probe were performed, by orientating the EM-EC Scan probe along the orthogonal axes of a 3D system (omnidirectional response).

\subsection{Method of measurement}

To assess the accuracy of the prediction given by Radio Mobile application, we compared the data series obtained from measurements with the data series obtained by simulation. 
We used the Key Performance Indicator for the accuracy of a propagation prediction model:

- average error and standard deviation of predicted and measured field strengths;

- correlation between the string of predicted data and the string of measured field strength.

\section{Results and discussion}

The configuration of the network, of the equipment and the simulation parameters implemented in Radio Mobile, the quality of radio links, the location of measurement points in which the reception is made and of the broadcasting TETRA base station emitting in a channel with frequency $393 \mathrm{MHz}$, can be seen in Figure 3 .

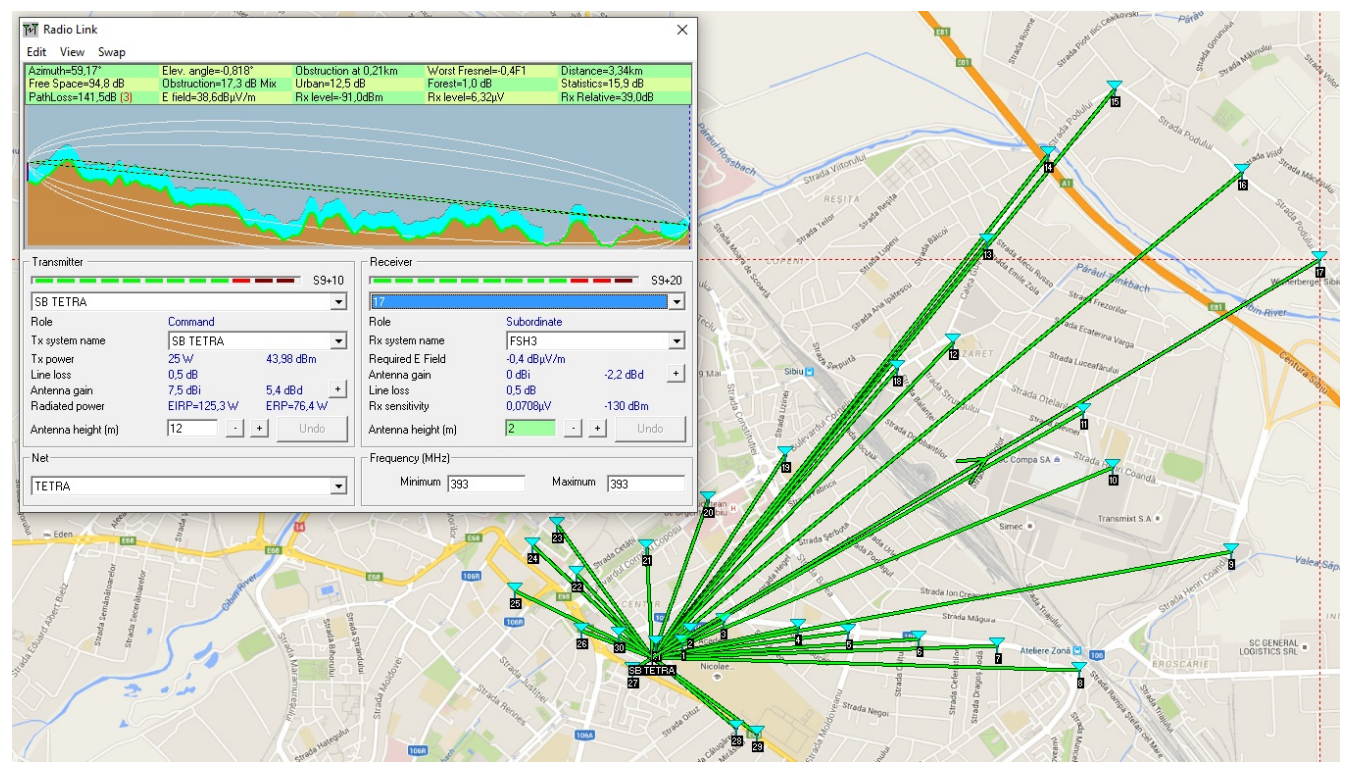

Figure 3. Links quality and positions of emission and reception points in the TETRA network simulated by Radio Mobile application

In the upper left corner of Figure 3, in the Radio Link tool, one can view the parameters of the radio link between the base station and the measuring point. For example, one observes that in reception point no. 17, the application forecasts a power level of $-91 \mathrm{dBm}$.
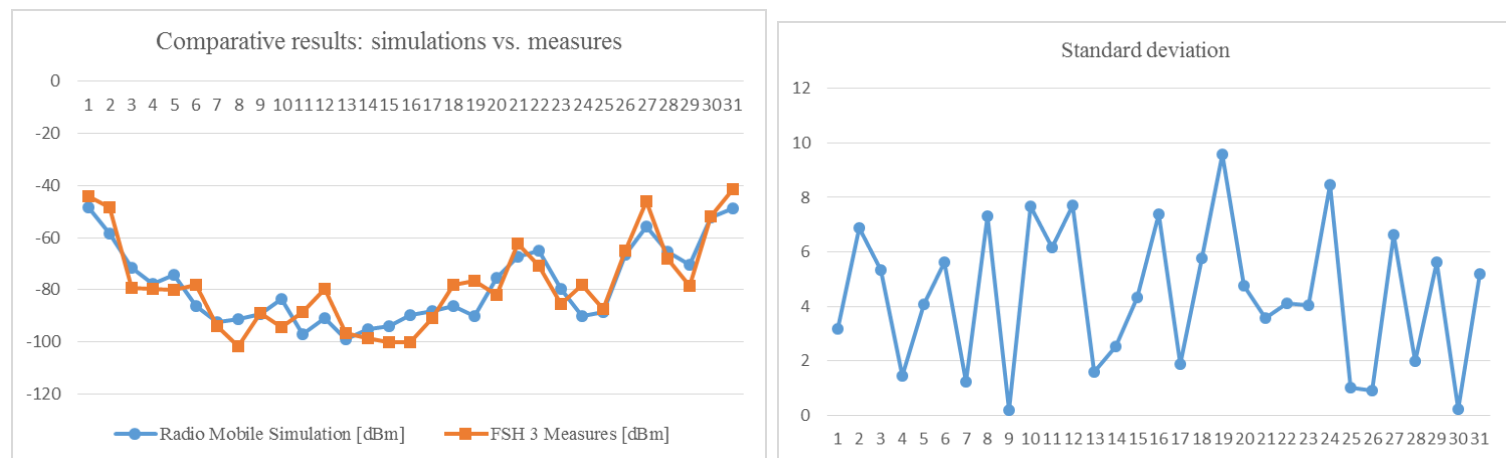

Figure 4. Comparative results and standard deviation

Signal power levels at the 31 reception locations obtained by Mobile Radio simulation and by measurement with
FSH3 analyzer are presented comparatively in Figure 4 (left). The results demonstrate that the values of the two sets of data are 
subject to the same trend, with very low differences.

In the second graphic of Figure 4 (right), one can see the standard deviation values in each location of reception. Mean standard deviation was $4.4 \mathrm{~dB}$ while the maximum variation was $9.6 \mathrm{~dB}$.

Given that in the urban propagation environment, modeled by Rayleigh, for an estimated probability of link achievement of $90 \%,[12]$ indicates a fading margin of at least $8.2 \mathrm{~dB}$, the values we obtained - for the range of variation of the standard deviation and for the mean standard deviations - are very good.

\section{Conclusions}

The value of 0.907 for correlation coefficient obtained between measured and simulated data sets of power levels, together with the value of $4.4 \mathrm{~dB}$ for standard deviation of the mean, we do appreciate that Radio Mobile application ensures a high degree of confidence regarding forecasting capabilities of radio coverage for the analyzed situation. We believe that this is due to the recognized quality of the ITM PTP radio propagation model and to the high resolution available in the elevation maps allowing a very realistic $3 \mathrm{D}$ modeling of land in the city.

\section{References}

[1] ETS 300 392-1 Radio Equipment and Systems (RES); Trans-European Trunked Radio (TETRA); Voice plus Data $(V+D) ;$ Part 1: General network design, ETSI, TC-RES, ICS: $33.020,30.060 .50$

[2] EN 300 392-2 V2.1.1 (2000-12), Terrestrial Trunked Radio (TETRA); Voice plus Data $(V+D)$; Part 2: Air Interface (AI), ETSI 650 Route des Lucioles F-06921 Sophia Antipolis Cedex - FRANCE

[3] http://www.teleplanglobe.no/telecom/astrix

[4] http://www.atdi.co.uk/software/software-applications/

[5] http://www.cplus.org/rmw/english1.html

[6] radiomobile.pelmew.nl

[7] Bouleanu I., Gheorghevici M., Helbet R., The quality of the prediction for the NVIS propagation with ITS-HF Propagation, în Electrotehnică, Electronică, Automatică (EEA) nr. 1/2016, ISSN 1582-5175 pp.97-105

[8] Walden M. C, Comparition of propagation predictions and measurements for mildaltitude $\mathrm{HF}$ near-vertical incidence sky wave links at $5 \mathrm{MHz}$, Radio Sci., 47, RS0L09, doi: 10.1029/2011RS004914

[9] Radio Mobile Handbook http://www.antennex.com/Sshack/radmob/radmob.htm

[10] http://www.tetrahaberlesme.com.tr/Tunc/Tetra/role/MTS2/MTS2.pdf

[11] http://www.kathrein-scala.com/catalog/K751637.pdf

[12] Graham A. W., Kirkman N. C., Paul P. M., Mobile Radio Network Design in the VHF and UHF Bands: A Practical Approach, John Wiley \& Sons, The Atrium, Southern Gate, Chichester, West Sussex PO19 8SQ, England, 2007 